\title{
Suitability of Nondestructive Testing of Asphalt Concrete for Detecting the Impact of Moisture Damage
}

\author{
Saad Issa Sarsam \\ Sarsam and Associates Consult Bureau, Baghdad-Iraq \\ Email: saadisasarsam@coeng.uobaghdad.edu.iq
}

\begin{abstract}
:
Asphalt pavement susceptibility to moisture damage is considered as a major issue in the durability and service life of the roadway. Quick and nondestructive testing of asphalt concrete pavement are the major concern for predicting its suitability for evaluation. In the present investigation, nondestructive test has been implemented to detect the moisture damage issue of asphalt concrete mixture. Asphalt concrete specimens were prepared using Marshall method. Aggregates gradation of wearing, binder and base course was implemented for the preparation of the specimens. Specimens were tested for ultrasonic pulse velocity before and after practicing the moisture damage procedure. The variations of seismic modulus among various gradation before and after the moisture damage were considered as a criterion for moisture damage and related to tensile strength ratio TSR. It was observed that the pulse velocity decline by a range of (11 to 16) for asphalt concrete after moisture damage. It was concluded that the Seismic modulus as calculated from the ultrasonic pulse velocity test was effective in distinguishing the impact of moisture damage. The seismic modulus at optimum asphalt content decline by (34.7, 46.7, and 52.6) \% after moisture damage for wearing, binder, and base course mixtures respectively. The ultrasonic pulse velocity test is recommended for assessing the susceptibility of asphalt concrete mixture to moisture damage.
\end{abstract}

Keywords:

asphalt concrete; moisture damage; ultrasonic pulse velocity; seismic modulus

\section{Introduction}

Moisture damage due to stripping of binder is considered as a major distress of asphalt pavements and plays an important role in pavement design and construction. Besides, the performance and durability of the pavements are seriously affected due to the moistureinduced damage. Moisture damage can result from adhesive failure (failure of the bond between the asphalt binder and the aggregate), cohesive failure (failure within binder itself), or a combination of both adhesive and cohesive failures as reported by Hossain and Roy, (2018). The moisture damage of the hot mix asphalt was assessed by jimoh et al., (2014) at the laboratory room temperature of $25^{\circ} \mathrm{C}$. Destructive (DT) and non-destructive (NDT) tests were carried out on laboratory Marshall Specimens of an asphalt mix prepared for a specified pavement wearing course. The nondestructive test was accomplished with the portable ultrasonic nondestructive digital indicating tester. It was concluded that NDT method gave a more consistent result than the destructive, thereby recommended as a better-quality control scheme for flexible pavement. The ultrasonic pulse wave velocity test was evaluated by Birgisson et al., (2003) as a possible tool for monitoring the changes in the integrity of asphalt concrete mixtures due to moisture conditioning. The results show that the small strain modulus obtained with the ultrasonic pulse wave velocity test appears to be sensitive to changes in mixture integrity due to moisture. It was concluded that the ultrasonic pulse wave velocity test may be used as an indicator of damage in specimens as well as a quick monitoring device for detecting changes in the integrity of mixtures due to exposure to moisture. Arabani et al., (2009) investigated the effects of Hot Mix Asphalt parameters on wave propagation and 
its related parameters and established graphical procedures for estimating the stiffness properties of Hot Mixed Asphalt (HMA) mixtures.

The Ultrasonic Pulse Velocity UPV test usually requires lesser time, while the needed equipment for the test is relatively inexpensive as reported by Goel and Das, (2008). Arepalli, (2018) evaluated a conditioning and a test method that can be used to detect moisture susceptible mixes and to understand the combined problem of moisture induced material loss and change in strength/stiffness of the mix. Ultrasonic Pulse Velocity (UPV), Dynamic Modulus in Indirect tensile mode, and Indirect Tensile Strength (ITS) tests were utilized. It was reported that the Ultrasonic Pulse Velocity (UPV) test was found to be sensitive to changes in mixes because of the moisture conditioning process. It was concluded that threshold values of seismic modulus of pre-conditioning mixes can be utilized. A combination of the UPV and the Indirect Tensile Strength (ITS) test can be used successfully to evaluate the resistance of HMA against moisture damage. Some examples for such techniques are the application of ultrasonic pulse wave velocity (UPV), impact resonance (IR), resonant column (RC), and acoustic emission (AE) tests for characterization of asphalt concrete strength and quality as addressed by Tavassoti-Kheiry et al., (2017). It was stated that repeatability of the UPV test is very high, both on the same specimen and among the replicates. Cheng et al. [49] used Ultrasonic Detection Method (UDM) to determine the ultrasonic wave transmission velocity through asphalt mixtures at different temperatures and water contents.

The modulus of asphalt concrete mixtures was determined using the UPV and Marshall specimens while considering the geometric density and bulk density of the specimens respectively. However, the experimental results data reveal that considering bulk density can give higher reliability to determine modulus of asphalt mix as stated by Majhi et al., (2017). Tavassoti and Baaj, (2020) stated that studying the Tensile Strength Ratio (TSR) or loss of indirect tensile strength (ITS) due to moisture conditioning of specimens has been the most used method in North America. Review of case studies indicates major shortcomings of this technique. For instance, in many cases a mix may pass the minimum TSR requirements in the laboratory but would fail in the field and vice-versa. The provides a critical review of the existing methods for evaluation of moisture damage in asphalt mixtures along with their strengths and weaknesses for this purpose. Copeland et al., (2007) described the water damage in asphalt concrete mixtures as the cohesive failure in the mastic, adhesive failure at the asphalt-aggregate interface, and breakdown of aggregates.

The UPV method appeared to provide sensitivity in detecting stripping damage effects for specimens with low air-void contents as reported by Barnes and Trottier, (2010). Five theories can explain adhesion phenomena as stated by Omar et al., (2020), theory of mechanical interlocking, theory of weak boundary layers, theory of electrostatic, theory of chemical bonding, and theory of thermodynamics. It was concluded that factors that influence the asphalt mixture in resisting moisture damage vary due to the variation in the materials' properties, mixture properties, construction conditions, and field factors after construction. The chemical, physical, thermodynamic, and electrostatic properties of bitumen and aggregate are different from one type to another, and their behavior varies in dry and wet conditions, leading to confusion in understanding how to resist moisture damage. The primary cause of moisture damage in Hot Mix Asphalt mixture (HMA) is its cohesive failure and/or adhesive failure of aggregates and asphalt binder interface as reported by Airey and Choi, (2002). Mechanical test was implemented by Medina et al, (2018) for determining the dynamic moduli of hot-mix asphalt concrete (HMA). The dynamic moduli across multiple temperatures were determined using ultrasonic pulse velocity (UPV) test conducted on the same specimens. It 
was concluded that since the UPV test is considered simple as compared to the conventional dynamic modulus test. The sensitivity of the UPV test to the dynamic modulus and tensile strength determination was accounted for by the combined compressive and shear stresses comprising the surface wave motion. Pulse wave modulus testing is considered as a nondestructive testing method for field application to evaluate moisture damage-induced stiffness losses. Terzi et al, (2013) used the field and laboratory studies data to estimate the value of Marshall stability. Up to this aim, the pulse, Marshall properties, deflection, modulus of elasticity, density, and air void data were implemented as an input variable. The aim of this assessment is to study the suitability of implementing ultrasonic pulse velocity to detect the influence of moisture damage on asphalt concrete tensile strength and seismic modulus. Marshall Specimens will be prepared with various gradations and will practice the ultrasonic pulse wave traverse before and after moisture damage. The variation of seismic modulus before and after the moisture damage will be observed and related to tensile strength ratio TSR.

\section{Research Methods}

\subsection{Asphalt Cement}

Asphalt cement of 40-50 penetration grade was obtained from Dora refinery; the physical properties of the asphalt cement are presented in Table 1.

Table1. Physical Properties of Asphalt Cement

\begin{tabular}{|c|c|c|c|}
\hline Test procedure as per ASTM, (2015) & Result & Unit & $\begin{array}{c}\text { SCRB Specification, } \\
\mathbf{( 2 0 0 3 )}\end{array}$ \\
\hline Penetration $\left(25^{\circ} \mathrm{C}, 100 \mathrm{~g}, 5 \mathrm{sec}\right)$ ASTM D 5 & 40 & $1 / 10 \mathrm{~mm}$ & $40-50$ \\
\hline Ductility $\left(25^{\circ} \mathrm{C}, 5 \mathrm{~cm} / \mathrm{min}\right)$. ASTM D 113 & 156 & $\mathrm{Cm}$ & $\geq 100$ \\
\hline Softening point (ring \& ball). ASTM D 36 & 49 & ${ }^{\circ} \mathrm{C}$ & $50-60$ \\
\hline Specific gravity at 25 ${ }^{\circ} \mathrm{C}$, ASTM D 70 - 03 & 1.04 & - & - \\
\hline \multicolumn{4}{|c|}{ After Thin-Film Oven Test ASTM D-1754 } \\
\hline $\begin{array}{c}\text { Retained penetration of original, \%, ASTM D } \\
\text { 946 }\end{array}$ & 77.5 & $\%$ & $>55$ \\
\hline $\begin{array}{c}\text { Retained Ductility of original } \% \text { at } 25^{\circ} \mathrm{C}, \\
5 \mathrm{~cm} / \text { min, (cm) ASTM D-113 }\end{array}$ & 94 & $\%$ & $>25$ \\
\hline $\begin{array}{c}\text { Loss in weight }\left(163^{\circ} \mathrm{C}, 50 \mathrm{~g}, 5 \mathrm{~h}\right) \% \text { ASTM D- } \\
1754\end{array}$ & 0.75 & $\%$ & - \\
\hline
\end{tabular}

\subsection{Coarse and Fine Aggregate}

Coarse and fine aggregates are obtained from Al-Nibaee quarry. Such aggregates are locally available and usually used for pavement construction. Table 2 exhibit the physical properties of aggregates.

Table 2. Physical Properties of Al-Nibaee Coarse and Fine Aggregate

\begin{tabular}{|c|c|c|c|}
\hline Property & $\begin{array}{c}\text { ASTM, (2015) } \\
\text { Designation No. }\end{array}$ & $\begin{array}{c}\text { Coarse } \\
\text { Aggregates }\end{array}$ & $\begin{array}{c}\text { Fine } \\
\text { Aggregates }\end{array}$ \\
\hline Bulk specific gravity & C127-01 & 2.610 & 2.631 \\
\hline Apparent specific gravity & C127-01 & 2.641 & 2.680 \\
\hline Water absorption \% & C127-01 & 0.423 & 0.542 \\
\hline Wear \% (los Angeles abrasion) & C131-03 & 20 & ----- \\
\hline
\end{tabular}




\subsection{Mineral Filler}

Limestone dust was obtained from Karbala plant and used as mineral filler. The physical properties of the filler are listed in Table 3.

Table 3. Physical Properties of Mineral Filler (Limestone dust).

\begin{tabular}{|c|c|}
\hline Property & Value \\
\hline Bulk specific gravity & 2.617 \\
\hline$\%$ Passing Sieve No.200 & 94 \\
\hline Plasticity index (\%) & Non plastic \\
\hline
\end{tabular}

\subsection{Selection of Aggregate Gradation}

The implemented aggregate gradation follows the SCRB, (2003) Specification for dense graded base, binder, and wearing courses, with $(25,19$, and 12.5) $\mathrm{mm}$ nominal maximum size of aggregates respectively. Figure 1 exhibits the implemented aggregate gradations.

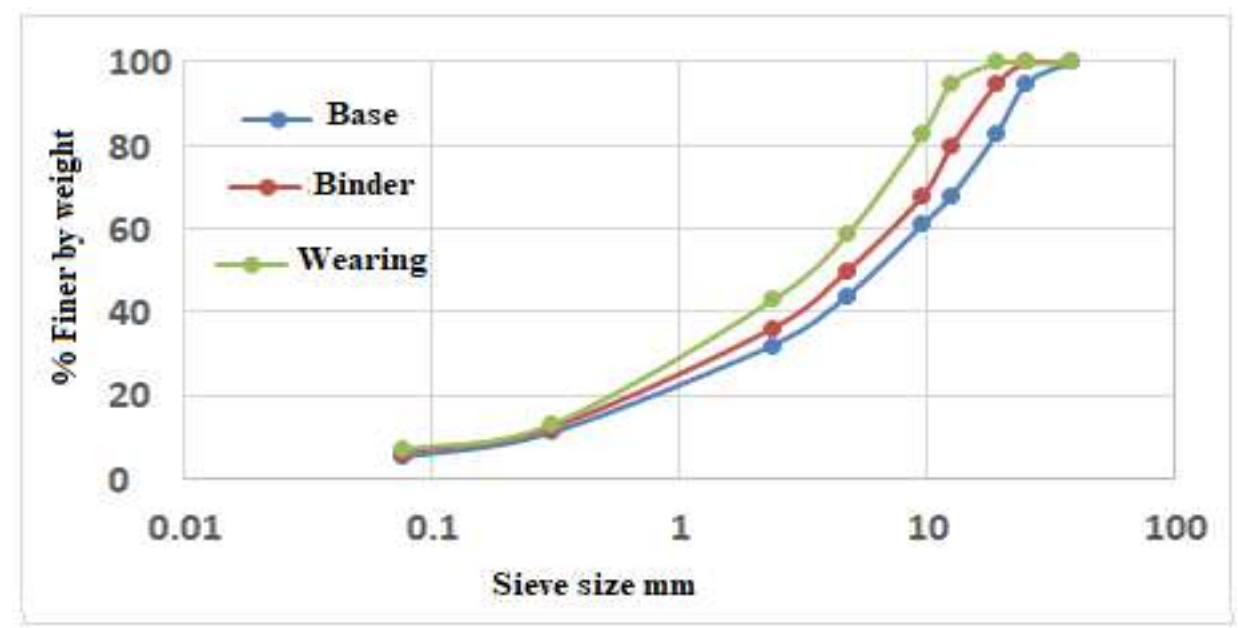

Figure 1. The aggregate gradation as per SCRB, (2003)

\subsection{Preparation of Hot Mix Asphalt Concrete}

The obtained aggregates were oven dried, then separated to different sizes by sieving, and stored separately in containers. Coarse and fine aggregates were combined with mineral filler to meet the specified gradations for various asphalt concrete layers as per SCRB, (2003) specifications presented in Figure 1. The combined aggregate mixture and asphalt cement were heated to $150^{\circ} \mathrm{C}$, then the asphalt cement was added to the heated aggregates to achieve the desired amount and mixed thoroughly using mechanical mixer for two minutes, until all aggregate particles were coated with thin film of asphalt binder. Marshall specimens were prepared in accordance with ASTM D1559, (2015) using 75 blows of Marshall hammer on each face of the specimen for wearing and binder course and 50 blows on each face for base course as recommended by SCRB, (2003). The optimum asphalt content for each layer was determined. Specimens with optimum asphalt content and $0.5 \%$ of asphalt above and below the optimum have been prepared for each pavement layer. Details of obtaining the optimum asphalt content could be found in Sarsam and Kadium, (2020). Similar specimen preparation procedure was adopted by Sarsam and AL Nuaimi, (2020). Figure 2 exhibit part of the prepared specimens. 


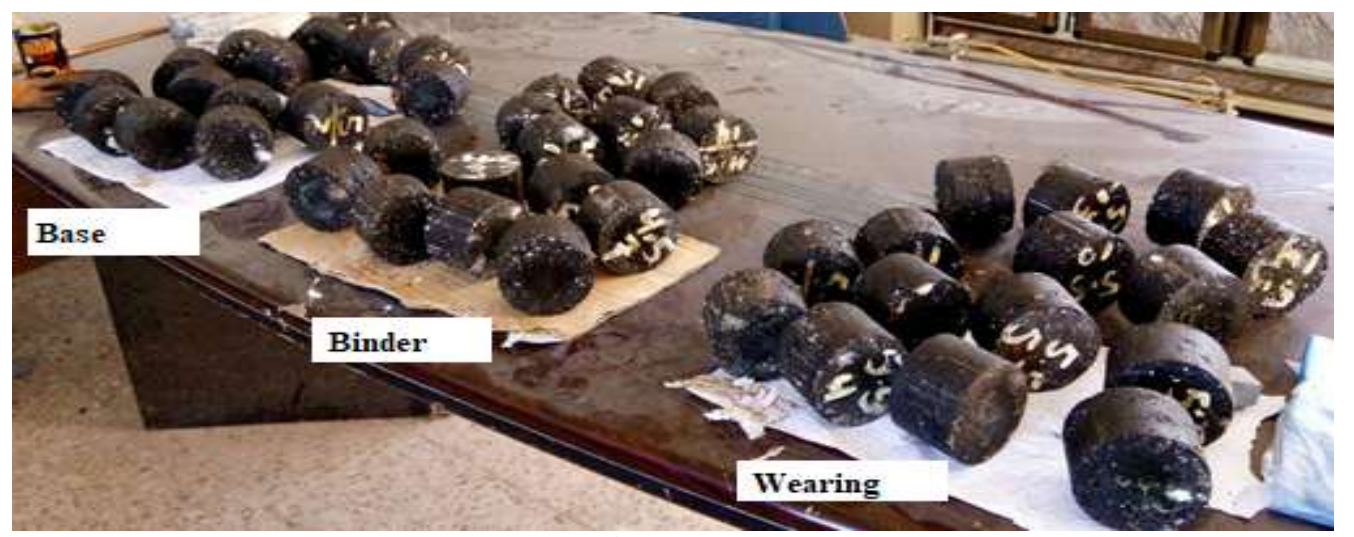

Figure 2. Part of the Prepared Specimens

\subsection{Ultrasonic Pulse Velocity Measurement}

The Portable Ultrasonic Nondestructive Indicating Tester (PUNDIT) was implemented in this investigation. The ultrasonic device consists of a pulse generator and a timing circuit, coupled with piezoelectric transmitting and receiving transducers. The device generates and receives ultrasonic waves and has a digital display of the results, a frequency of $54 \mathrm{kHz}$ and accuracy of 0.1 and the direct transmission arrangement technique were implemented throughout this investigation to measure the ultrasonic pulse velocity through the asphalt concrete specimens. Such frequency was recently employed by Arabani and Kheiry, (2006-a). The propagation of the low-strain mechanical waves generated by the device assesses the state of materials without causing damage. The pulser and receiver were placed on opposite parallel surfaces of the specimen after calibration as recommended by ASTM C597, (2015). An electrical timing unit measures the time taken for a pulse to travel through the asphalt concrete with an accuracy of $\pm 0.1 \mu$ seconds. A thin layer of Vaseline oil was applied on the surface of the tested points to act as a couplet between the transducer and the asphalt concrete specimen's surface and to prevent dissipation of transmitted energy. The pulse transit path length of the specimen (which is the specimen's thickness) was measured accurately, and the time taken by the wave in traversing the specimen was recorded. The distance between the transducers, was divided by the measured time and the ultrasonic pulse waves velocity was obtained. Eight readings were performed and averaged for each specimen. The ultrasonic pulse velocity test setup is demonstrated in Figure 3.

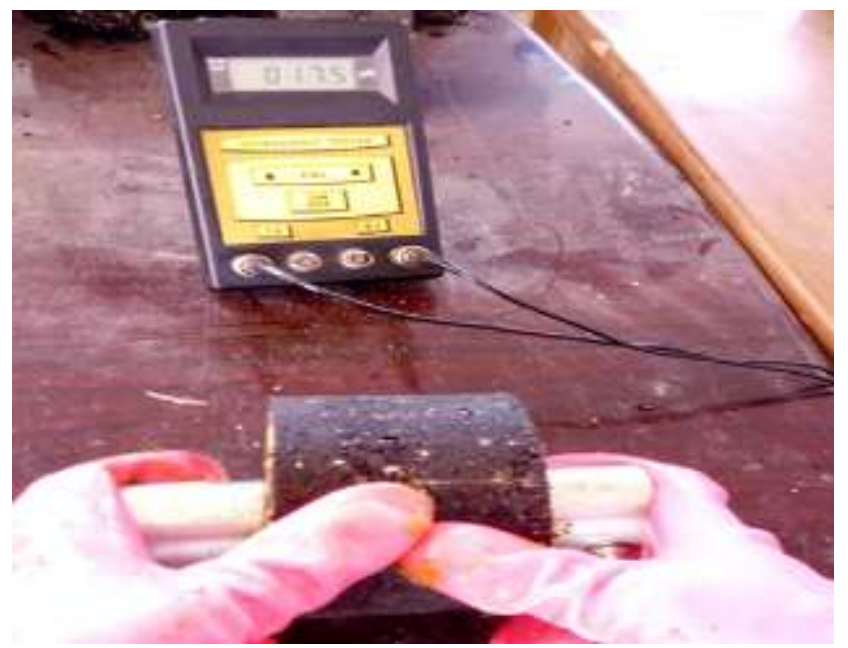

Figure 3. Ultrasonic Pulse Velocity Test Setup 


\subsection{Testing for Resistance to Moisture Damage}

The resistance to moisture damage of asphalt concrete specimens was assessed as per the procedure described by AASHTO, (2013); Sarsam and Hamdan, (2020); and Sarsam and Alwan, (2015). The specimens were divided into two groups, the first group was denoted as unconditioned specimens which was tested for Indirect Tensile Strength ITS at $25^{\circ} \mathrm{C}$. The second group of Asphalt concrete specimens were immersed in a water bath at $25^{\circ} \mathrm{C}$ and subjected to saturation under a vacuum pressure of $3.74 \mathrm{kPa}$ for ten minutes, then the specimens were removed from the water bath and stored into a deep freezer for 16 hours at (18 ${ }^{\circ}$ C. Afterword, Specimens were withdrawn from the deep freezer and allowed for thawing for 120 minutes in air, then transferred to a water bath and stored for 120 minutes at $60{ }^{\circ} \mathrm{C}$. Specimens were denoted as conditioned specimens then stored at $25^{\circ} \mathrm{C}$ for 120 minutes before testing for ITS.

\subsection{Indirect Tensile Strength Test ITS}

The indirect tensile strength test was conducted following the procedure of ASTM D6931, (2015); Marshall Specimens were stored in the water bath at $25^{\circ} \mathrm{C}$ for 30 minutes and then each specimen was subjected to ITS test after getting centered on the vertical diametrical plane between the two parallel loading strips of $12.7 \mathrm{~mm}$ width. Vertical compression load was applied at a loading rate of $50.8 \mathrm{~mm} / \mathrm{min}$ by Versa tester machine until the dial gage reading reached the maximum load resistance. The indirect tensile strength (ITS) was calculated as per ASTM D4123, (2015). Figure 4 demonstrates the indirect tensile strength test.

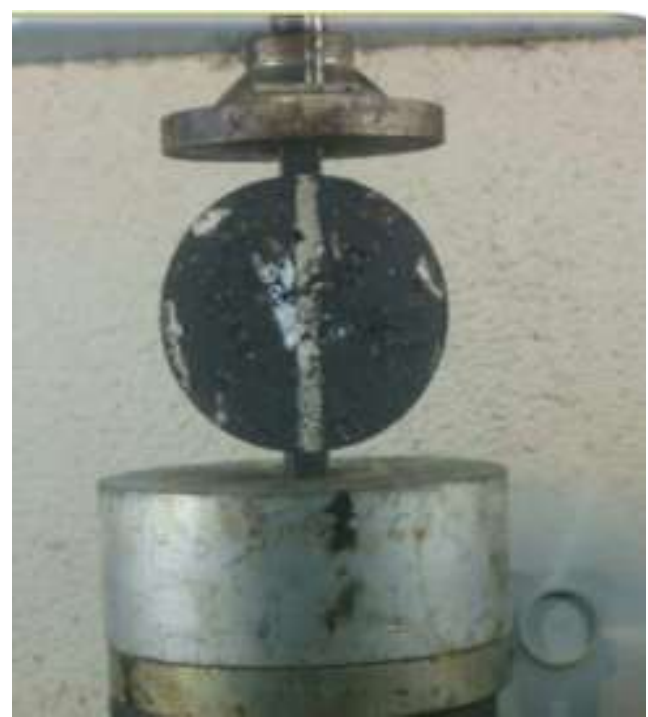

Figure 4. Indirect Tensile Strength Test Setup

\subsection{Determination of Seismic Modulus of Asphalt Concrete}

Asphalt concrete is a viscoelastic material, and the theory of elasticity can be used. The test was conducted at $25^{\circ} \mathrm{C}$ while the displacements of the asphalt concrete specimen and corresponding strains are very small, and the actual movements are very short in duration. For simplicity, the asphalt concrete mixture can be assumed as homogenous and isotropic solid as addressed by Birgisson et al., (2003), and Arabani and Kheiry, (2006-b). The velocity of the ultrasonic pulse is related to the modulus of the asphalt concrete. The Seismic Modulus can be determined as per TDOT, (2006); Gudmarsson, (2012). Once the time taken by the ultrasonic pulse to traverse the specimen is known, the seismic modulus can be calculated using equation (1), and the pulse velocity of longitudinal stress waves in the material is related to its elastic properties (Poisson ratio) and according to Medina. and Underwood, (2018). 
$\mathrm{Ev}=1.274 \times 10^{9} \frac{W H}{(D \text { tv })^{2}} \times \frac{(1+\mathrm{v})(1-2 v)}{(1-v)}$

where,

$\mathrm{E}_{\mathrm{V}}=$ Seismic modulus $(\mathrm{MPa})$

$H=$ Height of specimen $(\mathrm{mm})$

$W=$ Weight of specimen $(\mathrm{kg})$

$D=$ Dimeter of specimen $(\mathrm{mm})$

$\mathrm{tv}=$ Average travel time (microseconds)

$\mathrm{v}=$ Poisson ratio (assumed as $=0.4$ )

\section{Results and Discussions}

\subsection{Influence of Asphalt Concrete Mixture Type on Tensile Strength Ratio TSR \%}

Figure 5 demonstrates the influence of mixture type on Tensile Strength Ratio (TSR $\%$ ), it can be observed that the wearing course mixture with optimum binder content exhibits the highest TSR of $91 \%$ as compared with binder and base courses. The wearing and binder course mixtures shows higher sensitivity to the change in binder content as compared to the case of base course mixture. TSR \% decline to $(35,27$, and 25$) \%$ for wearing, binder, and base mixtures respectively when the asphalt content is lower by $0.5 \%$ from the optimum content. However, TSR \% decline to (38, 40, and 46) \% for wearing, binder, and base mixtures respectively when the asphalt content is higher by $0.5 \%$ from the optimum content. Wearing course mixture exhibit an acceptable TSR of (91, and 85) \% as per SCRB, (2003) requirements. However, the base course mixture exhibits low TSR value of $58 \%$. It was felt that the asphalt base course is not in contact with moisture and will not be subjected to stripping.

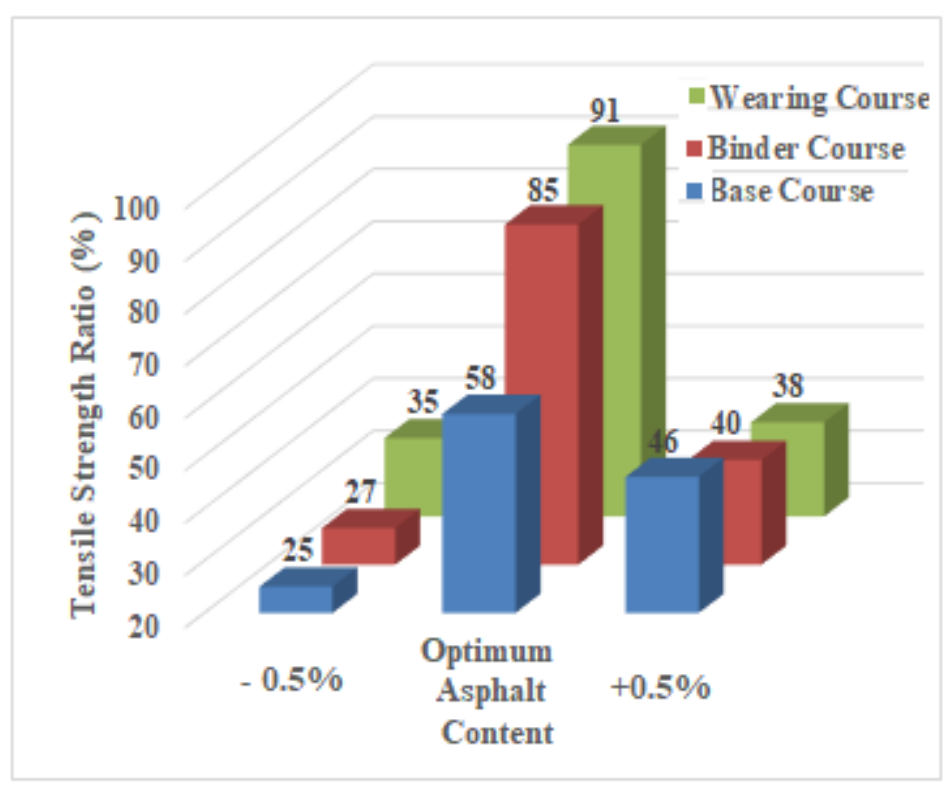

Figure 5. Influence of Mixture Type on TSR \% 


\subsection{Assessment of Seismic Modulus from Pulse Velocity}

As demonstrated in Figure 6, the pulse velocity for various courses (wearing, binder, and base) was in the range of $(3.1-4.5) \mathrm{mm} /$ microseconds before moisture damage (unconditioned) and decline to a range of $(3.1-3.8) \mathrm{mm} /$ microseconds for specimens after moisture damage (conditioned). This may be attributed to the stripping of asphalt film surrounding the aggregate particles, and initiation of more voids in the mixture. This behavior was further supported by the reduction in seismic modulus of asphalt concrete from a range of (10-21) GPa to (5-12) GPa after moisture damage. This could be attributed to the fact that stripping of asphalt film due to reduction of adhesion between asphalt and aggregates causes reduction in cohesion between aggregate particles. Similar finding was reported by Arepalli, (2018). It can be observed that the wearing course mixture of $12.5 \mathrm{~mm}$ nominal maximum size of aggregate exhibit higher seismic modulus than binder or base courses before and after practicing moisture damage process. Such findings agree well with the work reported by Tarefder and Yousefi, (2012). It can be noted that Wearing and binder courses mixtures have better stripping resistance than base course mixture for the same aggregate and binder types. This could be attributed to the variations in asphalt content and gradation. Similar finding was reported by Khedaywi and Al Kofahi, (2019).

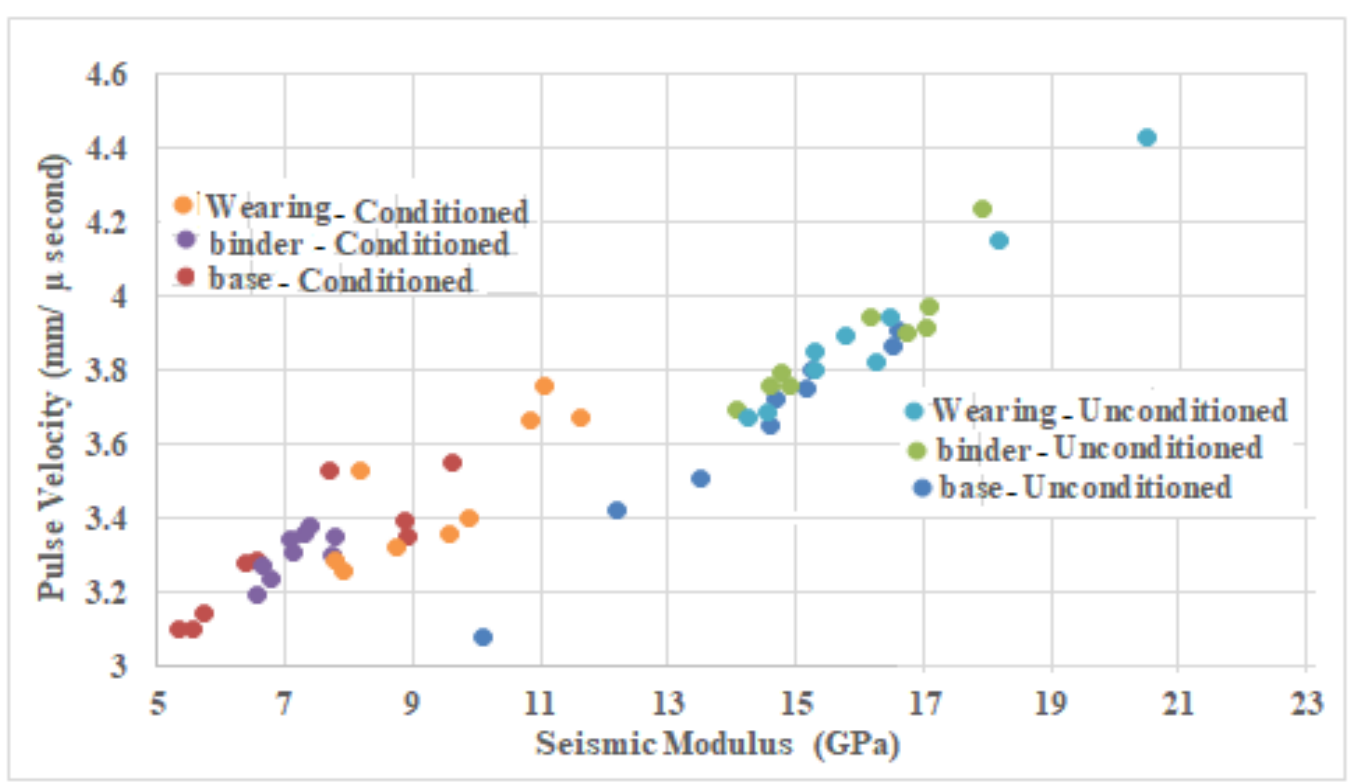

Figure 6. Seismic Modulus-Pulse Velocity Relationship

Table 4 presents the mathematical models relating the pulse velocity with seismic modulus for asphalt concrete before and after practicing the moisture damage process.

Table 4. Mathematical models

\begin{tabular}{|l|l|l|l|l|}
\hline Mixture Type & Unconditioned & $\mathrm{R}^{2}$ & Conditioned & $\mathrm{R}^{2}$ \\
\hline Wearing Course & $\mathrm{Y}=1.851+0.1248 \mathrm{X}$ & 0.98 & $\mathrm{Y}=2.651+0.090 \mathrm{X}$ & 0.75 \\
\hline Binder Course & $\mathrm{Y}=1.944+0.121 \mathrm{X}$ & 0.97 & $\mathrm{Y}=2.443+0.108 \mathrm{X}$ & 0.69 \\
\hline Base Course & $\mathrm{Y}=2.133+0.110 \mathrm{X}$ & 0.82 & $\mathrm{Y}=2.605+0.097 \mathrm{X}$ & 0.52 \\
\hline Combined Model & $\mathrm{Y}=1.865+0.125 \mathrm{X}$ & 0.95 & $\mathrm{Y}=2.674+0.086 \mathrm{X}$ & 0.75 \\
\hline $\mathrm{Y}=$ Pulse Velocity $(\mathrm{mm} /$ microsecond), $\mathrm{X}=$ Seismic Modulus $(\mathrm{GPa})$ & \\
\hline
\end{tabular}


It can be observed that under unconditioned process (before practicing moisture damage), the asphalt concrete mixture of various layers exhibits an excellent correlation, and the models can explain most of the variations in seismic modulus (over $82 \%$ ). However, after practicing moisture damage, the asphalt concrete mixture of various layers exhibits satisfactory correlation, and the models can explain (52 to 75 ) \% of the variations in seismic modulus.

\subsection{Influence of Moisture Damage on Seismic Modulus of Asphalt Concrete}

Figure 7 demonstrates the influence of moisture damage on seismic modulus of asphalt concrete, it can be noted that the seismic modulus at optimum asphalt content decline by $(34.7,46.7$, and 52.6) \% after moisture damage for wearing, binder, and base course mixtures respectively. However, the seismic modulus of wearing course mixture is higher than that of binder and base course mixtures regardless of the moisture damage process.
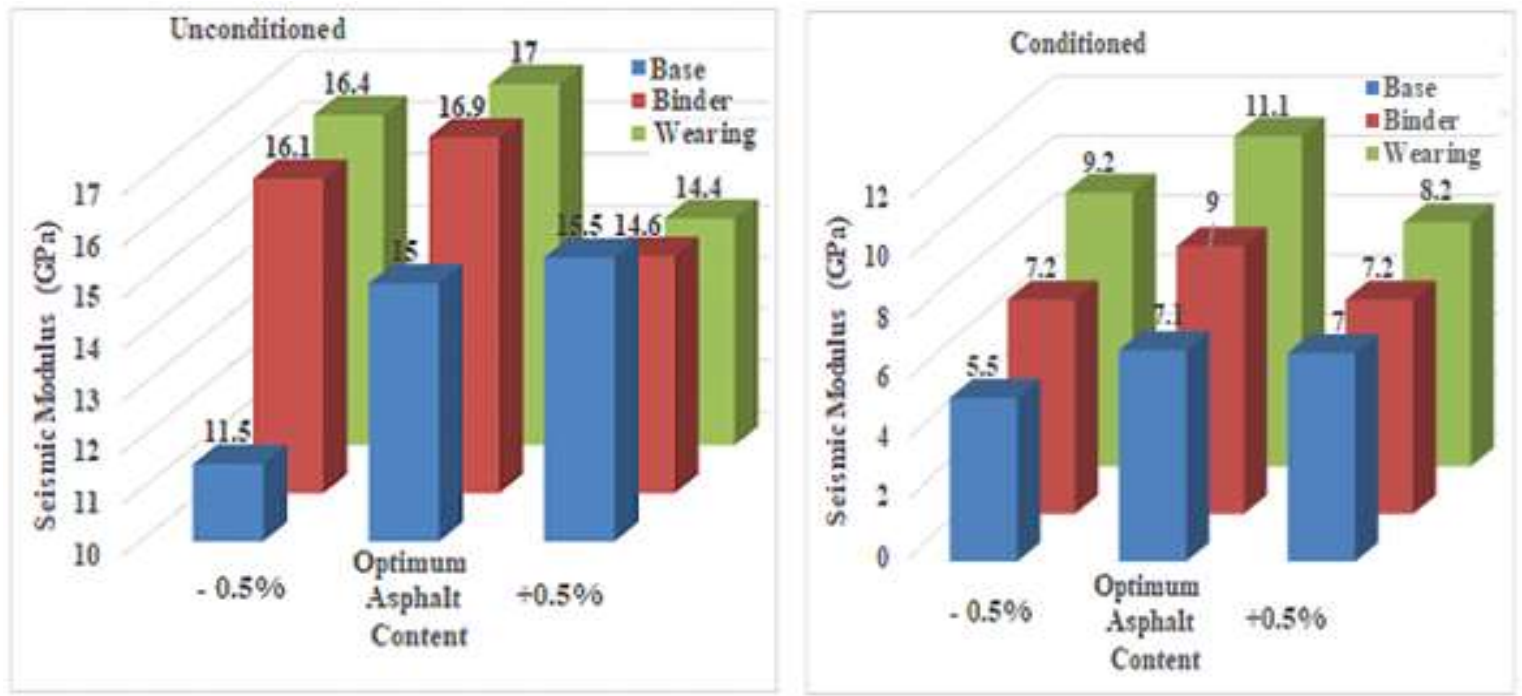

Figure 7. Influence of Moisture Damage on Seismic Modulus

\section{Conclusions}

Based on the limitations of materials and the testing program, the following conclusions may be drawn.

1 - The wearing and binder course mixtures shows higher sensitivity to the change in binder content as compared to the case of base course mixture.

2 - TSR $\%$ decline to $(35,27$, and 25$) \%$ and $(38,40$, and 46$) \%$ for wearing, binder, and base mixtures respectively when the asphalt content is lower or higher by $0.5 \%$ from the optimum content.

3- The pulse velocity for (wearing, binder, and base) was in the range of (3.1- 4.5) $\mathrm{mm} /$ microseconds before moisture damage and decline to a range of $(3.1-3.8)$ $\mathrm{mm} /$ microseconds for specimens after moisture damage.

4- The seismic modulus of asphalt concrete decline from a range of (10-21) GPa to (5-12) GPa after moisture damage.

5- The seismic modulus at optimum asphalt content decline by $(34.7,46.7$, and 52.6) $\%$ after moisture damage for wearing, binder, and base course mixtures respectively.

6- The developed mathematical models can explain most of the variations in seis mic modulus (over $82 \%$ ) before moisture damage. However, after practicing moisture damage, the models can explain (52 to 75 ) \% of the variations in seismic modulus. 


\section{References}

Hossain Z., and Roy S. (2018). Impacts of Moisture on Asphalt Properties. Project No. 17BASU03. Final Research Report. Tran-SET's website (http://transet.lsu.edu/).

Jimoh Y. A., Itiola I. O., and Afolabi A. A. (2014). Destructive and non-destructive determination of resilient modulus of hot mix asphalt under different environmental conditions. International Journal of Pavement Engineering, Volume 16, 2015 - Issue 10. P. 857-867. https://doi.org/10.1080/10298436.2014.964235.

Birgisson B., Roque R., Page G. (2003). Ultrasonic Pulse Wave Velocity Test for Monitoring Changes in Hot-Mix Asphalt Mixture Integrity from Exposure to Moisture January 1, Transportation Research Record: Journal of the Transportation Research Board, 1832, 173-181. Doi: 10.3141/1832-21. https://doi.org/10.3141/1832-21.

Arabani M., Kheiry P. T. and Ferdosi B. (2009). Laboratory Evaluation of the Effect of HMA Mixt Parameters on Ultrasonic Pulse Wave Velocities. Road Materials and Pavement Design Volume 10, 2009 - Issue 1. P. 223-232. https://doi.org/10.1080/14680629.2009.9690189.

Goel A., and Das A. (2008). Nondestructive testing of asphalt pavements for structural condition evaluation: a state of the art. Nondestructive Testing and Evaluation, 23:2,121 140, Doi. 10.1080/10589750701848697.

Arepalli U. M. (2018). A study of moisture induced material loss of hot mix asphalt (HMA). Ph.D. Dissertation. February, Worcester polytechnic institute.

Tavassoti-Kheiry P., Boz I., Chen X., Solaimanian M. (2017). Application of Ultrasonic Pulse Velocity Testing of Asphalt Concrete Mixtures to Improve the Prediction Accuracy of Dynamic Modulus Master Curve. Proceedings, Airfield and Highway Pavements. ASCE.

Cheng Y., Zhang P., Jiao Y., Wang Y., and Tao J. (2013). Damage simulation and ultrasonic detection of asphalt mixture under the coupling effects of water-temperature-radiation. Adv. Mater. Sci. Eng., Vol. 2013.

Majhi D., Karmakar S., Roy T. (2017). Reliability of Ultrasonic Pulse Velocity Method for Determining Dynamic Modulus of Asphalt Mixtures. ICEMS 2016, Materials Today: Proceedings 4, 9709-9712.

Tavassoti P., and Baaj H. (2020). moisture damage in asphalt concrete mixtures: state of the art and critical review of the test methods. Proceedings, Conference of soils and materials session, Transportation Association of Canada.

Copeland, A. R., Kringos, N., Youtcheff Jr, J. S., and Scarpas, T. (2007). Measurement of Aggregate-Mastic Bond Strength in Presence of Moisture: Combined ExperimentalComputational Study. Proc., Transportation Research Board 86th Annual Meeting.

Barnes, C. L., \& Trottier, J.-F. (2010). Evaluating laboratory-induced asphalt concrete moisture damage using surface waves. International Journal of Pavement Engineering, 11(6). 489-497. Doi:10.1080/10298430903578929.

Omar H. A., Izzi N., Yusoff M., Mubaraki M., Ceylan H. (2020). Effects of moisture damage on asphalt mixtures. Journal of traffic and transportation engineering; 7 ( 5 ) : P. 600 628. (http://creativecommons.org/licenses/by-nc-nd/4.0/).

Airey, G. D., and Choi, Y.-K. (2002). Art Report on Moisture Sensitivity Test Methods for Bituminous Pavement Materials. Road Materials and Pavement Design, 3(4), 355-372.

Medina. J. R., Underwood B. S., and Michael Mamlouk M. (2018). Estimation of Asphalt Concrete Modulus Using the Ultrasonic Pulse Velocity Test. Journal of Transportation Engineering, Part B: Pavements, ASCE, 144(2): 04018008.

Terzi S., Karasahin M., Gokova S., Tahta M., Morova N., and Uzun I. (2013). Asphalt concrete stability estimation from non-destructive test methods with artificial neural 
networks. Neural Computer \& Applications, 23:989-997. Doi 10.1007/s00521-012-10231.

ASTM, Road and Paving Materials, (2015). Annual Book of ASTM Standards, Volume 04.03, Standard test method for pulse velocity through concrete. ASTM C597-09, American Society for Testing and Materials, West Conshohocken, USA.

State Commission of Roads and Bridges SCRB, (2003). Standard Specification for Roads \& Bridges, Ministry of Housing \& Construction, Iraq.

Sarsam S. I. and Kadium N. S. (2020). Verifying Moisture Damage Impact in Asphalt Concrete with the Aid of Nondestructive Test NDT. Advances in Sciences and Engineering;12(1):13-20. https://doi.org/10.32732/ase.2020.12.1.13 .

Sarsam S., and AL Nuaimi S. (2020). Influence of Ageing on Flexible Pavement Interface Bond under Repeated Shear Stresses. Britain International of exact sciences journal. (BloEx Journal). Vol. 2, No. 2, May, P. 462-475. Doi: https://doi.org/10.33258/bioex.v2i2.219.

Arabani M., Kheiry T. P., (2006-a). A New Method for Determination Stiffness Modulus of HMA Mixtures, ISSA world Congress and International seminar on Asphalt pavement Maintenance Technologies, China.

AASHTO, (2013). Standard Specification for Transportation Materials and Methods of Sampling and Testing, American Association of State Highway and Transportation Officials, 14th Edition, Part II, Washington, D.C.

Sarsam S., and Hamdan R. (2020). Modeling the Influence of Surface Free Energy on Moisture Damage of Recycled Asphalt Concrete. Budapest international research in exact sciences (BirEx Journal). Vol.2, No. 2. April P.168-183. https://bircujournal.com/index.php/birex.

Sarsam S. and Alwan A. (2015). Properties of Super pave Asphalt Concrete Subjected to Impact of Moisture Damage, Journal of Engineering. Vol. 21 No.1. (P1-14).

Arabani M., Kheiry T. P., (2006-b). Evaluating the Use of Ultrasonic Pulse Velocity Test for Determination Dynamic Elastic Modulus of HMA Mixtures, Asphalt institute of Iran, 3rd national Congress on Asphaltic Materials.

TDOT. (2006). Quality Management of Flexible Pavement Layers with Seismic Methods: Test Methods. Texas Department of Transportation and the Federal Highway Administration Project Number 5-1735-01.

Gudmarsson A. (2012). Laboratory Seismic Testing of Asphalt Concrete. Licentiate Thesis KTH Royal Institute of Technology, School of Architecture and Built Environment, Department of Transport Science Division of Highway and Railway Engineering SE-100 44, Stockholm.

Tarefder R. A. and Yousefi S. S. (2012). Laboratory evaluation of moisture damage in asphalt, Can. J. Civ. Eng. 39: 104-115, NRC Research Press.

Khedaywi T. and Kofahi N. (2019). Utilization of the resilient modulus test to predict stripping of asphalt concrete mixture. International Journal of Civil Engineering and Technology (IJCIET), Volume 10, Issue 05, May pp. 706-726. http://www.iaeme.com/ijciet/issues.asp 